\title{
The Impact of Big Data Adoption on SMEs Performance
}

Mahdi Nasrollahi ( $\nabla$ m.nasrollahi@soc.ikiu.ac.ir)

Imam Khomeini International University https://orcid.org/0000-0003-4546-9059

Javaneh Ramezani

Universidade Nova de Lisboa Faculdade de Ciencias e Tecnologia

Mahmoud Sadraei

Stickman

\section{Research}

Keywords: Industry 4.0, Big Data Adoption, SMEs, Organizational Performance, Structural Equation Modelling

Posted Date: September 21st, 2020

DOl: https://doi.org/10.21203/rs.3.rs-66047/v1

License: (c) (i) This work is licensed under a Creative Commons Attribution 4.0 International License. Read Full License

Version of Record: A version of this preprint was published at Big Data and Cognitive Computing on November 24th, 2021. See the published version at https://doi.org/10.3390/bdcc5040068. 


\section{Abstract}

The notion of Industry 4.0 encompasses the adoption of new information technologies that enable an enormous amount of information to be digitally collected, analysed, and exploited in organizations to make better decisions. Therefore, finding how organizations can adopt big data components to improve their performance became a relevant research area. This issue is becoming more pertinent for SMEs. This study investigates the impact of big data adoption on SMEs performance by obtaining the required data from experts. The quantitative investigation followed a mixed approach, including survey data from 224 managers from Iranian SMEs, and a SEM methodology for the data analysis. Results showed that 12 factors affected the BDA in SMEs. BDA can affect both operational performance and economic performance, there has been no support for the influence of BDA and economic performance on social performance. Finally, the study implications and findings are discussed alongside future research avenues and limitations.

\section{Introduction}

In recent years industries are shifting towards the age of Industry 4.0 or digital transformation. This transformation results from contributions from various engineering and manufacturing disciplines and merging the technologies, including artificial intelligence and machine learning, neuro-technologies, mobile and cloud computing, sensing, and other "exponential technologies". In the era of Industry 4.0, growing exponentially, data significantly impact obtaining new knowledge, fostering business innovation, and achieving competitive advantage. Accordingly, the utilization of big data with distinct capabilities, features, and specifications has grown rapidly in industrial contexts because of engineering developments and, more specifically, in computer science and information technology. Big data with developing data mining techniques supports the so-called smartness of everything everywhere by facilitating realtime, dynamic, self-adaptive, and precise control capabilities (Ramezani \& Camarinha-Matos, 2019; Kopanakis, Vassakis, \& Mastorakis, 2016; Chatterjee, Fornasiero, Ramezani \& Ferrada, 2019).

Theoretically, there is a wide-ranging discussion about the impact of information technology (IT) on the organization's performance. Although in such a trend, IT contributes to firms' competitiveness, but its role is still relatively unclear (Kohli, \& Grover, 2008). In conditions that information flows in the internet and virtual networks are established with high speed and intensity, the level of information of individuals as the main audiences of this data flow is affected by this trend. Thus, the emergence of new ideas and creativity from each person and staff (Bondarouk \& Ruel, 2009) and consequently, the necessity creation of a new structure for the current organizations in the global society is inevitable and worthy of serious review and contemplation.

In addition to the hardware available in each job system that requires to be updated in line with the current turbulent era, the software related to each job also needs to be reviewed and updated. On the other hand, "Knowledge management cycle (KMC)" models became essential issues for organizations in the volatile and globalized word in order to make valuable decisions and achieve business outcomes. KMC is a strategic tool in fostering the (symbiosis of implicit and explicit) knowledge and creating a proper perception of it in organizations (Kopanakis, Vassakis, \& Mastorakis, 2016).

Big data is one of the topics that has been considered by managers and decision-makers nowadays due to the high speed and volume of data exchange to develop productivity in industries (Nasrollahi, \& Ramezani, 2020). Although, in recent years, several studies have been conducted on various methods of data analysis and storage, particularly in the field of industry, and big data has become an important issue in different sectors (Yadegaridehkordi et al., 2020). Still, in small and medium enterprises (SMEs), less attention has been paid to it, and it is a relatively unknown issue for the managers of these organizations. Nevertheless, studies have shown that technology and innovation are strategic priorities for SMEs' growth, and among them, big data will be one of the main drivers (Sen, Ozturk, \& Vayvay, 2016).

Since the competitive market becomes more complicated day by day, the organizational decision-makers increasingly rely more and more upon big data for the firm's utilization, understanding process performance, product performance analysis, inventory management optimization, and so on (Hazen et al. 2014). Hence, it is necessary to ensure the quality and reliability of the used data. Lack of adequate and reliable data may lead to inappropriate decisions, missing organizational plans and opportunities, and damage to the organization (Warth, Kaiser, \& Kügler, 2011).

Big data adoption (BDA) enables organizations to create a clear picture of customers and their demands in order to make well-informed decisions in designing marketing strategies (Manyika et al., 2011). SMEs, in turn, also require big data to analyse the market and predict customer behavior. Big data in SMEs can lead to increased flexibility, efficiency, responsiveness, and the ability to anticipate and meet customer needs, thus providing organizations a competitive edge (Sen et al., 2016). Adoption of big data is dependent upon technological, organization, managerial, and environmental factors and positively influences firm performance (Frisk \& Bannister, 2017; Verma \& Bhattacharyya, 2017).

Notably, developed countries have conducted most research on BDA, so we need more studies in developing countries (Baig, Shuib, \& Yadegaridehkordi, 2019; Brock \& Khan, 2017; Yadegaridehkordi et al., 2020). Therefore, in the present study, we try to evaluate the impact of big data adoption on SMEs' performance in developing countries, an issue that has not been studied yet.

Thereupon, in this study, besides developing a comprehensive model and describing how big data components affect performance, it is helped formulate theoretical basics in this field and confirm previous studies. Generally, one of the aims of this study is to demonstrate the importance of adopting big data in SMEs as a strategic requirement. To achieve this goal, the remainder of this article is structured as follows. The second section provides a brief overview of the theoretical basis and related works in the literature to achieve this goal. The third section describes the research method, statistical population, and the samples under study. In the fourth section, the research findings are presented. Finally, in the last section, the conclusion and suggestions for further research are presented.

\section{Literature Review}


They provide a base for future Big Data research for SMEs by investigating critical potentials and threats that need to be addressed. Also, they suggested potential practices to seize the full potential of Big Data in SMEs (Sen, Ozturk, \& Vayvay, 2016). A study showed that companies that developed technological and managerial capabilities of BDA perform better than other companies (Ferraris, Mazzoleni, Devalle, \& Couturier, 2019). In another study, it was stood out that good infrastructure is the most critical factor for big data adoption (Silva et al., 2019). Sun et al. (2018), by content analysis, first identified 26 factors affecting big data adoption in firms and then provided a framework to help decision-making about BDA in organizations. Another study studied the adoption rate of big data in the US SMEs, which its results show that SMEs are very interested in using business analytics. Tian, Hassan, and Razak (2017) reported that BD could be a source of economic strength in the future as the development of BD has changed China's financial markets by creating a variety of financial and monetary services and tools. They predicted that existing structures would undergo serious changes.

Al Tawara and Gide (2016) investigated the effects of "mobile technology (MT)" and "big data-based social media marketing (SMM)" adoption in Jordanian SMEs. They conducted a review of MT practices using SMM in SME organizations to determine various variables that could impact the success of Big data-based social media platforms adoption in SMEs. Another study examined the importance of big data in the "data-driven innovation orientation" of organizations. The results showed that the knowledge generated from big data processes improves organizational performance and enables organizational decision-makers to resolve issues innovatively (Kopanakis, Vassakis, \& Mastorakis, 2016).

Following a hybrid approach using data collection with a survey of managers and three case studies, Mikalef, Boura, Lekakos, and Krogstie (2019) studied various resources and contextual factors that drive performance increases due to investing in big data analytics. Finally, applying a "fuzzy-set qualitative comparative analysis" method, four different patterns of components in big data analytic resources were identified that lead to high performance. The impact of big data analytics on Romanian companies' supply chain performance was studied by Oncioiu et al. (2019). Also, there have been some challenges, such as identifying new tools and technologies such as cloud computing and security technologies that companies, to achieve proper performance within the supply chain, are intended to implement.

Maroufkhani et al. (2019) provided a systematic review of big data analytics studies to identify various factors that influence big data adoption on organizations and determine different performance types that big data may improve. Mbassegue, Escandon-Quintanilla, and Gardoni (2016) discussed how big data would enable SMEs to improve their competitiveness and performance and the challenges they might face when adopting these technologies. In another study, the researchers identified barriers preventing SMEs from the successful adoption of big data and proposed a maturity model for SMEs as a roadmap to structure data analytics (Coleman, Göb, Manco, Pievatolo, Tort-Martorell, \& Reis, 2016).

Despite the growing number of studies on big data adoption and firm performance, there are lacking in attempts to evaluate the impact of BDA on SMEs' performance; therefore, the present study can help to develop existing knowledge in this field.

\section{Research Methodology}

In attempt to create the conceptual research model (Fig. 1) the related literature, particularly research conducted by (Ogbuokiri, Udanor, \& Agu, 2015; Kopanakis, Vassakis, \& Mastorakis, 2016; Sen, Ozturk, \& Vayvay, 2016; Anwar, Khan, \& Shah, 2018; Ferraris, Mazzoleni, Devalle, \& Couturier, 2019; Mikalef, Boura, Lekakos, \& Krogstie, 2019; Oncioiu et al., 2019; Maroufkhani et al., 2019), have been studied. Finally, according to our previous work (Nasrollahi and Ramezani 2020), it was found that 51 factors in 12 groups affect the big data adoption in organizations. Table 1 provides definitions of the constructs used in the model. Therefore, in the proposed model, first, the impact of this group of factors on big data adoption is tested. Then the big data adoption effect on organizational performance is investigated. In this model, big data components are independent variables, and organizational performance variables, including economic performance (ECP), operational performance (OPP), social performance (SOP), and organizational performance (ORP) are dependent variables. However, the organizational performance variable is defined as the final dependent variable in the model. 


\begin{tabular}{|c|c|}
\hline Construct & Definition \\
\hline $\begin{array}{l}\text { Feature factors } \\
\text { (FEF) }\end{array}$ & Including: Trainability, Perceived simplicity, Observability, Complexity, and Data quality and integration. \\
\hline $\begin{array}{l}\text { Organizational } \\
\text { factors (ORF) }\end{array}$ & Including: Organizational data environment, Business strategy orientation, Firm size, and Industry type. \\
\hline $\begin{array}{l}\text { Utility factors } \\
\text { (UTF) }\end{array}$ & Including: Perceived compatibility, Appropriateness, Perceived benefits (advantage), Relative advantage, and Perceived usefulness. \\
\hline $\begin{array}{l}\text { Technological } \\
\text { factors (TEF) }\end{array}$ & $\begin{array}{l}\text { Including: Technology readiness/ technology resources, Wireless technology, Availability of big data tools, Internal versus external } \\
\text { technologies, IS competence/IT structure (infrastructure), Technological capability, and Network challenges. }\end{array}$ \\
\hline $\begin{array}{l}\text { Stakeholders } \\
\text { factors (STF) }\end{array}$ & $\begin{array}{l}\text { Including: Vendor support, Competitive (Perceived industrial) pressure, Government support, laws and policy, Trading partner } \\
\text { adoption/ readiness, and IS fashion. }\end{array}$ \\
\hline $\begin{array}{l}\text { Financial } \\
\text { factors (FIF) }\end{array}$ & Including: Perceived financial readiness, Perceived cost, and Cost of adoption. \\
\hline $\begin{array}{l}\text { Processing } \\
\text { factors (PRF) }\end{array}$ & Including: system integration, Security and privacy, Data control, Predictive analytics accuracy, and Interpret unstructured data. \\
\hline $\begin{array}{l}\text { Cultural factors } \\
\text { (CUF) }\end{array}$ & Including: Organizational (learning) culture, information security culture, and Decision-making culture. \\
\hline $\begin{array}{l}\text { Wisdom factors } \\
\text { (WIF) }\end{array}$ & Including: IT expertise, Knowledge about big data, and big data awareness. \\
\hline $\begin{array}{l}\text { Environmental } \\
\text { factors (ENF) }\end{array}$ & Including: Supply chain connectivity, Risks of outsourcing, Market turbulence, and Marketing and inventory. \\
\hline $\begin{array}{l}\text { Managerial } \\
\text { factors (MAF) }\end{array}$ & Including: Leaders' attitude towards change, Management support for big data, Change efficacy, and Willingness to change. \\
\hline $\begin{array}{l}\text { Skills factors } \\
\text { (SKF) }\end{array}$ & Including: Human resources, Staffing, and Training. \\
\hline $\begin{array}{l}\text { Economic } \\
\text { performance } \\
(E C P)\end{array}$ & $\begin{array}{l}\text { Economic performance reflects the firm's ability to reduce costs associated with purchasing materials, energy consumption, waste } \\
\text { management, environmental fines, etc. (Green Jr, Zelbst, Bhadauria, \& Meacham, 2012). }\end{array}$ \\
\hline $\begin{array}{l}\text { Operational } \\
\text { performance } \\
\text { (OPP) }\end{array}$ & $\begin{array}{l}\text { Operational performance (OPP) is related to the firm's capability to increase product distribution efficiency to customers (Zhu, Sarkis, } \\
\& \text { Lai, 2008). }\end{array}$ \\
\hline $\begin{array}{l}\text { Social } \\
\text { performance } \\
\text { (SOP) }\end{array}$ & $\begin{array}{l}\text { Social performance (SP) reflects the status of organizational beliefs about social responsibilities, social accountability methods, } \\
\text { policies, plans, and the evident outcomes associated with the organization's social relationships (Younis, Sundarakani, \& Vel, 2016). }\end{array}$ \\
\hline $\begin{array}{l}\text { Organizational } \\
\text { performance } \\
\text { (ORP) }\end{array}$ & Financial and marketing and performance of the organization compared to the industry average (Green, \& Inman, 2005). \\
\hline
\end{tabular}

Based on the literature review and conceptual model shown in Fig. 1, this study aims to test 20 hypotheses.

H1: Feature factors have a positive and direct impact on BDA.

H2: Organizational factors have a positive and direct impact on BDA.

H3: Utility factors have a positive and direct impact on BDA.

H4: Technological factors have a positive and direct impact on BDA.

H5: Stakeholders factors have a positive and direct impact on BDA.

H6: Financial factors have a negative and reverse impact on BDA.

H7: Processing factors have a positive and direct impact on BDA.

H8: Cultural factors have a positive and direct impact on BDA.

H9: Wisdom factors have a positive and direct impact on BDA.

H10: Environmental factors have a positive and direct impact on BDA.

H11: Managerial factors have a positive and direct impact on BDA. 
H12: Skills factors have a positive and direct impact on BDA.

H13: BDA has a positive and direct impact on operational performance.

H14: BDA has a positive and direct impact on environmental performance.

H15: BDA has a positive and direct impact on social performance.

H16: Environmental performance has a positive and direct impact on operational performance.

H17: Environmental performance has a positive and direct impact on social performance.

H18: Environmental performance has a positive and direct impact on organizational performance.

H19: Operational performance has a positive and direct impact on organizational performance.

H20: Social performance has a positive and direct impact on organizational performance.

Evaluation items and validation of components affecting big data adoption and performance in the questionnaire have been extracted from various studies.

All items were rated on a 7-point Likert scale from 1 (completely disagree) to 7 (completely agree). In this study, field data drawn from an electronic questionnaire focusing on small and medium enterprises (SMEs) in Iran have been used. Therefore, this study's population consists of all senior managers and middle-level managers working in SMEs in Iran, who answered the questionnaires via email. Using the information available in the existing social network databases about experts and specialized such as industrial and scientific associations, irexpert.ir, Linkedln, etc. a total of 2863 emails have been sent in April 2020. During one month, 836 questionnaires were received, which among them, 612 were removed due to incompleteness. Finally, 224 senior and middle managers completed the questionnaire indicates that the response rate is $\% 7.8$.

\section{Results And Discussion}

Table 2 represents the demographic characteristics of the samples.

Table 2

Sample demographics

\begin{tabular}{|c|c|c|c|}
\hline \multicolumn{2}{|l|}{ Characteristic } & \multirow{2}{*}{$\begin{array}{l}\mathbf{N} \\
187\end{array}$} & \multirow{2}{*}{$\begin{array}{l}\% \\
83.5\end{array}$} \\
\hline Gender & Male & & \\
\hline & Female & 37 & 16.5 \\
\hline \multirow[t]{4}{*}{ Age } & Less than 30 & 33 & 14.7 \\
\hline & $31-40$ & 64 & 28.6 \\
\hline & $41-50$ & 88 & 39.3 \\
\hline & More than 50 & 39 & 17.4 \\
\hline \multirow[t]{4}{*}{ Work experience } & Less than 10 & 54 & 24.1 \\
\hline & $11-20$ & 78 & 34.8 \\
\hline & $21-30$ & 69 & 30.1 \\
\hline & More than 30 & 23 & 10.3 \\
\hline \multirow[t]{9}{*}{ Job title } & Chief executive officer & 19 & 8.5 \\
\hline & Chief operating officer & 31 & 13.8 \\
\hline & Factory manager & 41 & 18.3 \\
\hline & Marketing and sales manager & 24 & 10.7 \\
\hline & Purchase manager & 30 & 13.4 \\
\hline & Product manager & 10 & 4.5 \\
\hline & Logistic manager & 18 & 8.0 \\
\hline & Supply chain manager & 25 & 11.2 \\
\hline & Chief information officer & 26 & 11.6 \\
\hline Total & & 224 & 100 \\
\hline
\end{tabular}

Page 5/12 
Table 3 shows the different industries in which respondents are working there. Respondents were from 20 various sectors.

Table 3

Sample industry

\begin{tabular}{|c|c|c|c|}
\hline \multicolumn{2}{|l|}{ Description } & $\mathbf{N}$ & Percentage \\
\hline \multicolumn{2}{|c|}{ Food and Kindred Products } & 27 & 12.1 \\
\hline \multicolumn{2}{|c|}{ Food and Kindred Products } & 16 & 7.1 \\
\hline \multicolumn{2}{|c|}{ Water, Sewer, Pipeline \& Power Line } & 3 & 1.3 \\
\hline \multicolumn{2}{|c|}{ Electrical equipment and component manufacturing } & 6 & 2.7 \\
\hline \multicolumn{2}{|c|}{ detergent, cosmetic and hygienic products } & 22 & 9.8 \\
\hline \multicolumn{2}{|c|}{ sanitary ware } & 5 & 2.2 \\
\hline \multicolumn{2}{|c|}{ automotive parts manufacturing } & 16 & 7.1 \\
\hline \multicolumn{2}{|c|}{ Medical equipment manufacturing } & 7 & 3.1 \\
\hline \multicolumn{2}{|c|}{ Machine-Made Carpets manufacturing } & 3 & 1.3 \\
\hline \multicolumn{2}{|l|}{ Textile mills } & 3 & 1.3 \\
\hline \multicolumn{2}{|c|}{ Tobacco Products manufacturing } & 4 & 1.8 \\
\hline \multicolumn{2}{|c|}{ Lumber \& Wood Products manufacturing } & 7 & 3.1 \\
\hline \multicolumn{2}{|c|}{ Office Furniture manufacturing } & 10 & 4.5 \\
\hline \multicolumn{2}{|c|}{ Papers \& Allied Products manufacturing } & 6 & 2.7 \\
\hline \multicolumn{2}{|c|}{ Chemicals \& Allied Products manufacturing } & 17 & 7.6 \\
\hline \multicolumn{2}{|c|}{ Pharmaceutical Preparations manufacturing } & 12 & 5.4 \\
\hline \multicolumn{2}{|c|}{ Plastics, Rubber and Synth Resins manufacturing } & 21 & 9.4 \\
\hline \multicolumn{2}{|c|}{ Concrete, Gypsum \& Plaster Products manufacturing } & 10 & 4.5 \\
\hline \multicolumn{2}{|c|}{ Leather \& Leather Products manufacturing } & 12 & 5.4 \\
\hline \multicolumn{2}{|c|}{ Transportation equipment manufacturing } & 17 & 7.6 \\
\hline \multirow[t]{2}{*}{ Ownership } & Private & 138 & 61.7 \\
\hline & Government and Semi-Government & 86 & 38.4 \\
\hline \multicolumn{2}{|l|}{ Total } & 224 & 100 \\
\hline
\end{tabular}

Prior to the hypothesis test, kolmogorov-Smirnov (K-S) test was performed to evaluate the data's normality at the significance level of \%5. As indicated in Table 5, the significance level for all structures is greater than \%5. Thus, all data are normally distributed, and it is possible to use the structural equation modelling for the hypotheses test. Furthermore, Table 4 shows the mean and standard deviation of each variable and Cronbach Alpha value for measuring the validity of the questionnaire. 
Table 4

Normality (K-S) test, Descriptive statistics, and Validity test

\begin{tabular}{|c|c|c|c|c|c|c|c|c|c|}
\hline Construct & $\mathbf{N}$ & K-S & Sig. & $\begin{array}{l}\text { Number of } \\
\text { items }\end{array}$ & Mean & $\begin{array}{l}\text { Standard } \\
\text { deviation }\end{array}$ & $\mathbf{a}$ & $\begin{array}{l}\text { Composite } \\
\text { reliability (CR) }\end{array}$ & $\begin{array}{l}\text { Average Variance } \\
\text { Extracted (AVE) }\end{array}$ \\
\hline Feature factors & 224 & 2.107 & 0.358 & 5 & 3.084 & 1.093 & 0.755 & 0.849 & 0.693 \\
\hline Organizational factors & 224 & 1.982 & 0.382 & 4 & 3.407 & 1.002 & 0.983 & 0.760 & 0.601 \\
\hline Utility factors & 224 & 1.838 & 0.083 & 5 & 3.826 & 1.078 & 0.907 & 0.852 & 0.527 \\
\hline Technological factors & 224 & 2.005 & 0.237 & 7 & 3.152 & 0.933 & 0.834 & 0.780 & 0.592 \\
\hline Stakeholders factors & 224 & 2.409 & 0.192 & 5 & 3.333 & 0.980 & 0.927 & 0.822 & 0.679 \\
\hline Financial factors & 224 & 2.080 & 0.261 & 3 & 3.457 & 0.964 & 0.947 & 0.795 & 0.685 \\
\hline Processing factors & 224 & 1.567 & 0.211 & 5 & 3.517 & 1.239 & 0.944 & 0.860 & 0.773 \\
\hline Cultural factors & 224 & 2.333 & 0.307 & 3 & 3.621 & 1.005 & 0.941 & 0.796 & 0.639 \\
\hline Wisdom factors & 224 & 1.585 & 0.370 & 3 & 3.784 & 0.927 & 0.979 & 0.853 & 0.825 \\
\hline Environmental factors & 224 & 1.699 & 0.426 & 4 & 3.419 & 1.141 & 0.818 & 0.922 & 0.698 \\
\hline Managerial factors & 224 & 2.144 & 0.255 & 4 & 3.678 & 1.107 & 0.906 & 0.741 & 0.705 \\
\hline Skills factors & 224 & 2.180 & 0.291 & 3 & 3.606 & 1.159 & 0.829 & 0.931 & 0.820 \\
\hline $\begin{array}{l}\text { Economic performance } \\
\text { (ECP) }\end{array}$ & 224 & 1.600 & 0.435 & 6 & 3.114 & 0.954 & 0.753 & 0.819 & 0.541 \\
\hline $\begin{array}{l}\text { Operational performance } \\
\text { (OPP) }\end{array}$ & 224 & 2.371 & 0.283 & 5 & 3.829 & 1.208 & 0.758 & 0.814 & 0.674 \\
\hline Social performance (SOP) & 224 & 1.953 & 0.253 & 5 & 3.458 & 1.095 & 0.883 & 0.725 & 0.766 \\
\hline $\begin{array}{l}\text { Organizational } \\
\text { performance (ORP) }\end{array}$ & 224 & 1.836 & 0.118 & 7 & 3.804 & 1.078 & 0.877 & 0.793 & 0.575 \\
\hline
\end{tabular}

Table 5

Model Fit Statistics

\begin{tabular}{|llllllll|}
\hline Criterion & \multirow{2}{*}{ varvec $^{2}$} & RMSEA & GFI & AGFI & NFI & NNFI & CFI \\
\hline Result & 234.84 & 0.041 & 0.961 & 0.957 & 0.973 & 0.935 & 0.942 \\
\hline
\end{tabular}

Because of the large number of constructs and the small sample size, the proposed conceptual model has been evaluated using the structural equation modelling method. LISREL 9.30 software was used to complete both the confirmatory factor analysis required to appraise the measurement model and the structural analysis needed to assess the structural model due to the significant model fit information existing.

Table 5 shows a summary of descriptive statistics. All the correlation coefficients shown in Table 6 are significant at the \%1 significance level. 
Table 6

Correlation coefficient matrix

\begin{tabular}{|c|c|c|c|c|c|c|c|c|c|c|c|c|c|c|c|c|}
\hline & FEF & ORF & UTF & TEF & STF & FIF & PRF & CUF & WIF & ENF & MAF & SKF & ECP & OPP & SOP & ORP \\
\hline FEF & 0.882 & & & & & & & & & & & & & & & \\
\hline ORF & 0.380 & 0.829 & & & & & & & & & & & & & & \\
\hline UTF & 0.291 & 0.612 & 0.812 & & & & & & & & & & & & & \\
\hline TEF & 0.273 & 0.391 & 0.399 & 0.880 & & & & & & & & & & & & \\
\hline STF & 0.471 & 0.412 & 0.482 & 0.726 & 0.840 & & & & & & & & & & & \\
\hline FIF & 0.516 & 0.614 & 0.464 & 0.647 & 0.631 & 0.823 & & & & & & & & & & \\
\hline PRF & 0.440 & 0.454 & 0.690 & 0.642 & 0.584 & 0.439 & 0.781 & & & & & & & & & \\
\hline CUF & 0.500 & 0.712 & 0.578 & 0.471 & 0.489 & 0.575 & 0.347 & 0.796 & & & & & & & & \\
\hline WIF & 0.451 & 0.546 & 0.559 & 0.635 & 0.531 & 0.567 & 0.353 & 0.561 & 0.814 & & & & & & & \\
\hline ENF & 0.542 & 0.318 & 0.632 & 0.598 & 0.402 & 0.346 & 0.317 & 0.434 & 0.555 & 0.826 & & & & & & \\
\hline MAF & 0.380 & 0.496 & 0.720 & 0.634 & 0.432 & 0.343 & 0.509 & 0.678 & 0.315 & 0.420 & 0.790 & & & & & \\
\hline SKF & 0.428 & 0.631 & 0.694 & 0.450 & 0.328 & 0.515 & 0.458 & 0.436 & 0.612 & 0.575 & 0.490 & 0.874 & & & & \\
\hline ECP & 0.628 & 0.701 & 0.590 & 0.506 & 0.412 & 0.469 & 0.585 & 0.502 & 0.477 & 0.501 & 0.619 & 0.433 & 0.819 & & & \\
\hline OPP & 0.227 & 0.563 & 0.448 & 0.409 & 0.641 & 0.457 & 0.632 & 0.559 & 0.429 & 0.463 & 0.559 & 0.340 & 0.332 & 0.834 & & \\
\hline SOP & 0.589 & 0.538 & 0.527 & 0.485 & 0.418 & 0.308 & 0.596 & 0.429 & 0.306 & 0.403 & 0.367 & 0.452 & 0.570 & 0.497 & 0.803 & \\
\hline ORP & 0.519 & 0.607 & 0.376 & 0.373 & 0.531 & 0.475 & 0.337 & 0.399 & 0.320 & 0.480 & 0.424 & 0.510 & 0.4000 & 0.362 & 0.312 & 0.822 \\
\hline
\end{tabular}

Table 7 shows the results of the hypotheses test. The research model has been approximately accepted, and only two hypotheses rejected. The hypotheses $\mathrm{H} 1$ to 12 have been accepted in the first set, which indicates the impact of all identified factors on BDA. Acceptance of H13 and H14 reflects the influence of BDA on improving the organization's operational and economic performance. But, by rejecting $\mathrm{H} 15$, the impact of BDA on improving social performance cannot be verified. Approval of $\mathrm{H} 16$ shows the direct effect of ECP on operational performance. The study's findings do not approve the positive and significant impact of ECP on SOP, and for this reason, the $\mathrm{H} 17$ is rejected. Also, ECP has a positive and significant impact on ORP, and thus the H18 is verified. Finally, the $\mathrm{H} 19$ and H20, which indicated a direct and meaningful relationship of OPP and SOP whit ORP have also been accepted as expected.

Table 7

Structural model results

\begin{tabular}{|c|c|c|c|c|c|c|c|c|c|c|c|}
\hline \multicolumn{4}{|c|}{ Research Hypothesis } & \multirow{2}{*}{$\begin{array}{l}\text { Beta coefficients } \\
0.27^{\star \star}\end{array}$} & \multirow{2}{*}{$\begin{array}{l}\text { Status } \\
\text { Supported }\end{array}$} & \multicolumn{4}{|c|}{ Research Hypothesis } & \multirow{2}{*}{$\begin{array}{l}\text { Beta coefficients } \\
0.50^{\star \star}\end{array}$} & \multirow{2}{*}{$\begin{array}{l}\text { Status } \\
\text { Supported }\end{array}$} \\
\hline $\mathrm{H}_{1}$ & FEF & $\rightarrow$ & $\mathrm{BDA}$ & & & $\mathrm{H}_{11}$ & MAF & $\rightarrow$ & $\mathrm{BDA}$ & & \\
\hline $\mathrm{H}_{2}$ & ORF & $\rightarrow$ & $\mathrm{BDA}$ & $0.39^{\star *}$ & Supported & $\mathrm{H}_{12}$ & SKF & $\rightarrow$ & $\mathrm{BDA}$ & $0.31^{* *}$ & Supported \\
\hline $\mathrm{H}_{3}$ & UTF & $\rightarrow$ & $\mathrm{BDA}$ & $0.37^{\star \star}$ & Supported & $\mathrm{H}_{13}$ & $\mathrm{BDA}$ & $\rightarrow$ & OPP & $0.22^{\star *}$ & Supported \\
\hline $\mathrm{H}_{4}$ & TEF & $\rightarrow$ & $\mathrm{BDA}$ & $0.29^{* *}$ & Supported & $\mathrm{H}_{14}$ & $\mathrm{BDA}$ & $\rightarrow$ & ECP & $0.27^{* *}$ & Supported \\
\hline $\mathrm{H}_{5}$ & STF & $\rightarrow$ & $\mathrm{BDA}$ & $0.54^{\star \star}$ & Supported & $\mathrm{H}_{15}$ & $\mathrm{BDA}$ & $\rightarrow$ & SOP & 0.09 & Not Supported \\
\hline $\mathrm{H}_{6}$ & FIF & $\rightarrow$ & $\mathrm{BDA}$ & $0.49^{\star *}$ & Supported & $\mathrm{H}_{16}$ & ECP & $\rightarrow$ & OPP & $0.28^{\star *}$ & Supported \\
\hline $\mathrm{H}_{7}$ & PRF & $\rightarrow$ & $\mathrm{BDA}$ & $0.47^{\star \star}$ & Supported & $\mathrm{H}_{17}$ & ECP & $\rightarrow$ & SOP & 0.13 & Not Supported \\
\hline $\mathrm{H}_{8}$ & CUF & $\rightarrow$ & $\mathrm{BDA}$ & $0.40^{\star \star}$ & Supported & $\mathrm{H}_{18}$ & ECP & $\rightarrow$ & ORP & $0.43^{* *}$ & Supported \\
\hline $\mathrm{H}_{9}$ & WIF & $\rightarrow$ & $\mathrm{BDA}$ & $0.38^{\star *}$ & Supported & $\mathrm{H}_{19}$ & OPP & $\rightarrow$ & ORP & $0.39^{* *}$ & Supported \\
\hline $\mathrm{H}_{10}$ & ENF & $\rightarrow$ & $\mathrm{BDA}$ & $0.52^{* *}$ & Supported & $\mathrm{H}_{20}$ & SOP & $\rightarrow$ & ORP & $0.59^{* *}$ & Supported \\
\hline
\end{tabular}

\section{Conclusion}

Considering the rapid increase in volume and complexity of data due to the emerging advanced technologies and diversity of markets, paying attention to data acquisition and analysis has become an inevitable organizational approach. This issue is becoming more pertinent for SMEs, especially in developing countries that encounter limited resources and infrastructures. Accordingly, this study aimed to evaluate the impact of BDA on SMEs' performance. The 
literature was first reviewed to achieve this goal, and the most critical factors affecting BDA from previous studies were identified. In the next step, the impacts of BDA on performance were evaluated by obtaining the required data from experts.

This study yields valuable results by identifying the impacts of BDA on SMEs organizational performance. As summary, economic performance has a direct and positive impact on operational and organizational performance but has no significant effect on the organization's social performance. Finally, operational and social performance has a positive and significant impact on organizational performance. These results indicate that to improve various organizational performance such as ENP, OPP, SOP, and ORP, the senior management has to commit to BDA.

This study highlights the importance of understanding the BD's potential benefits for better decision-making and performance improvement because using BD creates many strategic and profitable opportunities for SMEs to succeed in a business ecosystem where competitiveness and innovation are key drivers. BD is a new opportunity for SMEs to use new data types to improve organizations' agility and solve complex problems and achieve better results and performance. As a result, fundamental changes occur in organizations' operations and performance, and consequently, organizations move towards more accurate and better information-based decision-making and modelling. Therefore, using BD is a crucial resource for SMEs to create value, new knowledge, and new processes and products.

The findings of this study provide managers a practical framework for decision-making about BDA. It can also be useful for managers and entrepreneurs, namely by offering them effective strategies and tips they can adopt and prioritize to improve the organizational performance. For instance, they can see how the various components of Big data affect an organization's performance. Researchers also may use this study to investigate various relevant hypotheses and improve the accuracy of future studies. Future research can develop variable measurement scales to validate the proposed model. As this model is likely one of the first models which evaluates the impact of BDA on SMEs Performance comprehensively, re-evaluating the model using data obtained from various samples could be interesting.

In this study, two major limitations could be addressed in future research to obtain more reliable results. In this study, mediator and moderator variables such as financial resources have not been investigated, and therefore other researchers can consider mediator and moderator variables. Also, variables such as industry type, organization size, and employee number can be regarded as control variables.

\section{Abbreviations}




\begin{tabular}{ll}
\hline SME: & Small and medium enterprise \\
\hline BDA: & Big data adoption \\
\hline IT: & Information technology \\
\hline KMC: & Knowledge management cycle \\
\hline SMM: & Social media marketing \\
\hline ECP: & Economic performance \\
\hline OPP: & Operational performance \\
\hline SOP: & Social performance \\
\hline ORP: & Organizational performance \\
\hline FEF: & Feature factors \\
\hline ORF: & Organizational factors \\
\hline UTF: & Utility factors \\
\hline TEF: & Technological factors \\
\hline STF: & Stakeholders factors \\
\hline FIF: & Financial factors \\
\hline PRF: & Processing factors \\
\hline CUF: & Cultural factors \\
\hline WIF: & Wisdom factors \\
\hline ENF: & Environmental factors \\
\hline MAF: & Managerial factors \\
\hline SKF: & Skills factors \\
\hline ECP: & Economic performance \\
\hline OPP: & Operational performance \\
\hline ORP: & Social performance \\
\hline Organizational performance \\
\hline S
\end{tabular}

\section{Declarations}

\section{Availability of data and materials}

Not Available.

\section{Competing interests}

The authors declare no conflict of interest.

\section{Funding}

The authors did not receive any specific funding for this study.

\section{Authors' contributions}

Mahdi Nasrollahi, Javaneh Ramezani \& Mahmoud Sadraei: conceptualization; methodology; data analysis; writing, reviewing and editing.

\section{Acknowledgements}

This work was supported by the Portuguese Foundation for Science and Technology (FCT) and the Center of Technology and Systems (CTS).

\section{References}

1. Al Tawara, A., \& Gide, E. (2016). A Comprehensive Analysis on the Adoption of Mobile Technology by Using Big Data-Based Social Media Marketing in SME Retailers in Jordan. Available at SSRN 2962990. 
2. Anwar, M., Khan, S. Z., \& Shah, S. Z. A. (2018). Big data capabilities and firm's performance: a mediating role of competitive advantage. Journal of Information \& Knowledge Management, 17(04), 1850045.

3. Baig, M. I., Shuib, L., \& Yadegaridehkordi, E. (2019). Big data adoption: State of the art and research challenges. Information Processing \& Management, 56(6), 102095.

4. Bondarouk, T. V., \& Ruël, H. J. (2009). Electronic Human Resource Management: challenges in the digital era. The International Journal of Human Resource Management, 20(3), 505-514.

5. Brock, V., \& Khan, H. U. (2017). Big data analytics: does organizational factor matters impact technology acceptance?. Journal of Big Data, 4(1), 21.

6. Camarinha-Matos, L. M., Fornasiero, R., Ramezani, J., \& Ferrada, F. (2019). Collaborative Networks: A Pillar of Digital Transformation. Applied Sciences, 9(24), 5431.

7. Coleman, S., Göb, R., Manco, G., Pievatolo, A., Tort-Martorell, X., \& Reis, M. S. (2016). How can SMEs benefit from big data? Challenges and a path forward. Quality and Reliability Engineering International, 32(6), 2151-2164.

8. Ferraris, A., Mazzoleni, A., Devalle, A., \& Couturier, J. (2019). Big data analytics capabilities and knowledge management: impact on firm performance. Management Decision, 57(8), 1923-1936.

9. Frisk, J. E., \& Bannister, F. (2017). Improving the use of analytics and big data by changing the decision-making culture. Management Decision, 55(10), 2074-2088.

10. Green, K. W., \& Inman, R. a. (2005). Using a just-in-time selling strategy to strengthen supply chain linkages. International Journal of Production Research, 43(16), 3437-3453.

11. Green Jr, K. W., Zelbst, P. J., Bhadauria, V. S., \& Meacham, J. (2012). Do environmental collaboration and monitoring enhance organizational performance?. Industrial Management \& Data Systems, 112(2), 186-205.

12. Hazen, B. T., Boone, C. A., Ezell, J. D., \& Jones-Farmer, L. A. (2014). Data quality for data science, predictive analytics, and big data in supply chain management: An introduction to the problem and suggestions for research and applications. International Journal of Production Economics, 154, $72-$ 80.

13. Kohli, R., \& Grover, V. (2008). Business value of IT: An essay on expanding research directions to keep up with the times. Journal of the association for information systems, 9(1), 23-39.

14. Kopanakis, I., Vassakis, K., \& Mastorakis, G. (2016, June). Big Data in Data-driven innovation: the impact in enterprises' performance. In Proceedings of 11th Annual MIBES International Conference (pp. 257-263).

15. Manyika, J., Chui, M., Brown, B., Bughin, J., Dobbs, R., Roxburgh, C., \& Byers, A. H. (2011). Big data: The next frontier for innovation, competition (Vol. 5, No. 6). and productivity. Technical report, McKinsey Global Institute.

16. Maroufkhani, P., Wagner, R., Wan Ismail, W. K., Baroto, M. B., \& Nourani, M. (2019). Big data analytics and firm performance: A systematic review. Information, 10(7), 226.

17. Mbassegue, P., Escandon-Quintanilla, M. L., \& Gardoni, M. (2016, July). Knowledge management and big data: Opportunities and challenges for small and medium enterprises (SME). In IFIP International Conference on Product Lifecycle Management (pp. 22-31). Springer, Cham.

18. Mikalef, P., Boura, M., Lekakos, G., \& Krogstie, J. (2019). Big data analytics and firm performance: Findings from a mixed-method approach. Journal of Business Research, 98, 261-276.

19. Nasrollahi, M., \& Ramezani, J. (2020). A Model to Evaluate the Organizational Readiness for Big Data Adoption. International Journal of Computers Communications \& Control, 15(3).

20. Ogbuokiri, B. O., Udanor, C. N., \& Agu, M. N. (2015). Implementing bigdata analytics for small and medium enterprise (SME) regional growth. IOSR Journal of Computer Engineering, 17(6), 35-43.

21. Oncioiu, I., Bunget, O. C., Türkeș, M. C., Căpușneanu, S., Topor, D. I., Tamaș, A. S., ... \& Hint, M. Ș. (2019). The impact of big data analytics on company performance in supply chain management. Sustainability, 11(18), 4864.

22. Rajabion, L. (2018, December). Application and Adoption of Big Data Technologies in SMEs. In 2018 International Conference on Computational Science and Computational Intelligence (CSCI) (pp. 1133-1135). IEEE.

23. Ramezani, J., \& Camarinha-Matos, L. M. (2019). A collaborative approach to resilient and antifragile business ecosystems. Procedia Computer Science, $162,604-613$.

24. Sen, D., Ozturk, M., \& Vayvay, O. (2016). An overview of big data for growth in SMEs. Procedia-Social and Behavioral Sciences, 235(1), $159-167$.

25. Silva, J., Hernández-Fernández, L., Cuadrado, E. T., Mercado-Caruso, N., Espinosa, C. R., Ortega, F. A., ... \& Delgado, G. J. (2019, July). Factors Affecting the Big Data Adoption as a Marketing Tool in SMEs. In International Conference on Data Mining and Big Data (pp. 34-43). Springer, Singapore.

26. Sun, S., Cegielski, C. G., Jia, L., \& Hall, D. J. (2018). Understanding the factors affecting the organizational adoption of big data. Journal of Computer Information Systems, 58(3), 193-203.

27. Tian, Z., Hassan, A. F. S., \& Razak, N. H. A. (2017). Big Data and SME financing in China. In 1st International Conference on Big Data and Cloud Computing (ICoBiC). Journal of Physics: Conf. Series 1018 (2018) 012002. Perlis, Malaysia.

28. Verma, S., \& Bhattacharyya, S. S. (2017). Perceived strategic value-based adoption of Big Data Analytics in emerging economy. Journal of Enterprise Information Management, 30(3), 354-382. 
29. Warth, J., Kaiser, G., \& Kügler, M. (2011, February). The impact of data quality and analytical capabilities on planning performance: insights from the automotive industry. In 10th International Conference on Wirtschaftsinformatik (pp. 322-331). Zurich, Switzerland.

30. Yadegaridehkordi, E., Nilashi, M., Shuib, L., Nasir, M. H. N. B. M., Asadi, S., Samad, S., \& Awang, N. F. (2020). The impact of big data on firm performance in hotel industry. Electronic Commerce Research and Applications, 40, 100921.

31. Younis, H., Sundarakani, B., \& Vel, P. (2016). The impact of implementing green supply chain management practices on corporate performance. Competitiveness Review, 26(3), 216-245.

32. Zhu, Q., Sarkis, J., \& Lai, K. hung. (2008). Confirmation of a measurement model for green supply chain management practices implementation. International Journal of Production Economics, 111(2), 261-273.

\section{Figures}

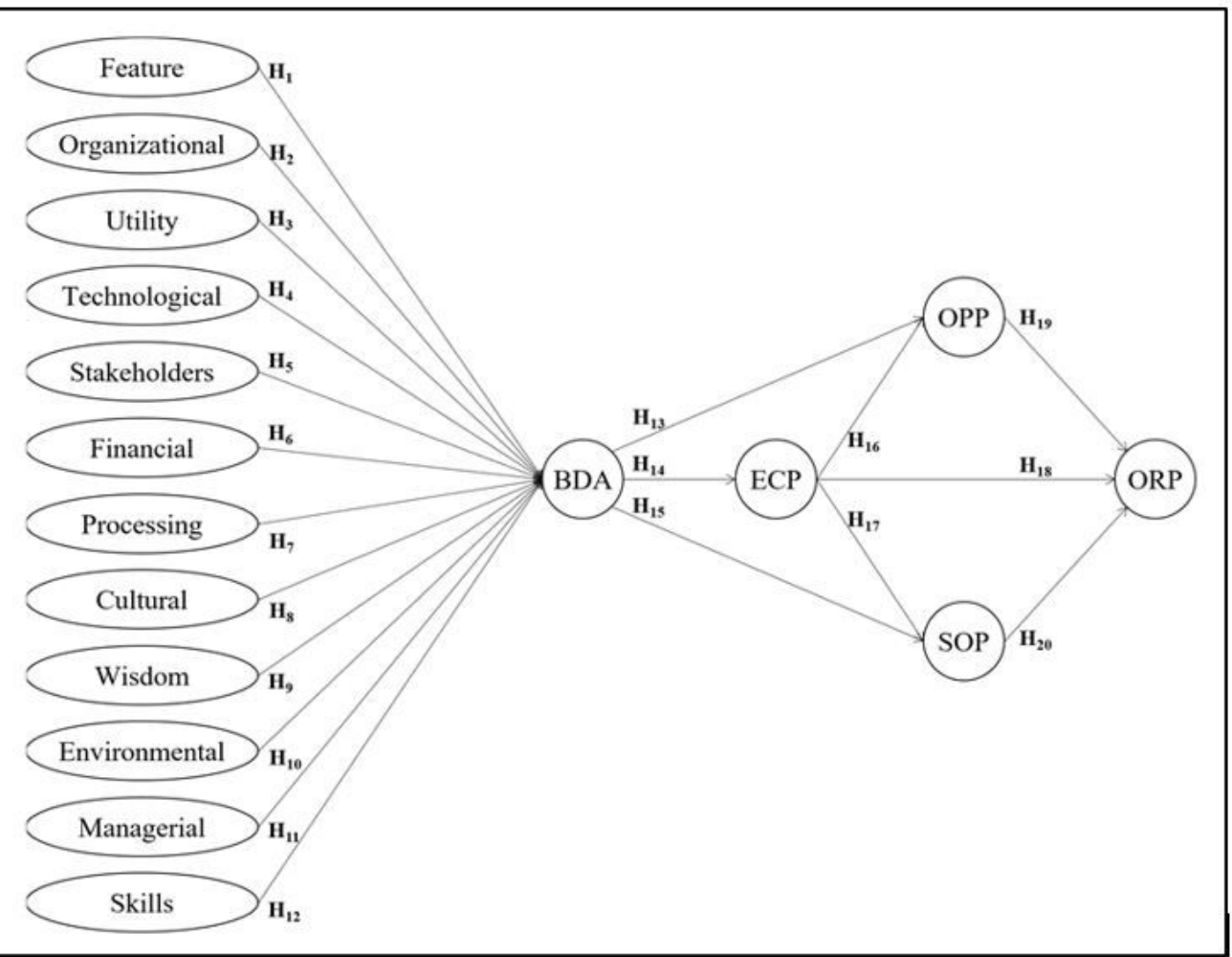

Figure 1

Conceptual model 